\title{
Effects of Low-Intensity Pulsed Ultrasound on Dental Implant Osseointegration: A Preliminary Report
}

\author{
Yakup Ustun a \\ Ozgur Erdogana \\ Mehmet Kurkcua \\ Tolga Akovab \\ İbrahim Damlara
}

\section{ABSTRACT}

Objectives: The aim of this pilot study was to evaluate the effects of low intensity pulsed ultrasound (LIPU) on dental implant osseointegration in a rabbit model using mechanical-histomorphometric methods and resonance-frequency analysis (RFA).

Methods: Twelve skeletally mature, male New Zealand rabbits $(3.4 \mathrm{~kg} \pm 0.5)$ were included in the study. A total number of 24 implants were placed bilaterally into the tibiae of the subjects. The right tibia of each rabbit received LIPU application $(20 \mathrm{~min} /$ day) while the left side received sham treatment. The study was carried on for six weeks and the rabbits were sacrificed in 7 days intervals (two rabbits for each week). The rabbits were categorized in the early or late osseointegration period according to their sacrification date. Comparisons between the groups were made using statistical analysis of histomorphometric analysis, resonance frequency analysis and mechanical tests.

Results: The histomorphometry parameters showed that the bone area and the bone volume values have significantly increased in the early osseointegration period and the bone-implant contact values have significantly increased in the late osseointegration period in the LIPU treated subjects when compared to the control group. RFA scores had mild increase in the LIPU group. However the difference was not statistically significant. Mechanical test results suggest an increased mechanical stability in the LIPU group as well.

Conclusions: Results of this pilot study indicate that low intensity pulsed ultrasound may have positive effects on osseointegration and stability of dental implants. (Eur J Dent 2008;2:254-262)

Key words: Osseointegration; Therapeutic ultrasound; Dental implant; Histomorphometry.

a Department of Oral \& Maxillofacial Surgery, Faculty of Dentistry, Cukurova University, Adana, Turkey.

b Department of Prosthodontics, Faculty of Dentistry, Cukurova University, Adana, Turkey.

- Corresponding author: Yakup Ustun Cukurova Universitesi, Dishekimligi Fakultesi, Agiz Dis Cene Hast. ve Cerrahisi AD, 01330 Balcali, Yuregir, Adana, Turkey.

Phone: +90 3223386354 Fax: +90 3223387331

E-mail: yustunđacu.edu.tr

\section{INTRODUCTION}

Endosseous dental implants may be considered as the most popular treatment option for partially and fully edentulous patients. It is generally accepted that implant success is primarily dependent upon or achieved by osseointegration, a direct contact between the implant surfaces and living bone. ${ }^{1}$ Numerous studies have been published regarding the efforts to increase the 
quality of osseointegration and shortening the osseointegration time. For this purpose, altering the surface and/or shape of the implant has been frequently researched and it has been shown that rough implant surfaces allow a higher percentage of bone-to-implant contact compared to implants with smooth surfaces. ${ }^{2,3}$ Further studies have been carried out to enhance implant osseointegration like dual acid etching of titanium, engineering of dental pulp cells on various implant surfaces and biomimetic implant coatings containing bone morphogenetic protein-2.4-6 Other methods studied to enhance endogenous bone healing around biomaterials are different forms of biophysical stimulations such as pulsed electromagnetic fields and low intensity pulsed ultrasounds (LIPU). ${ }^{7,8}$

Ultrasound is a form of energy that is transmitted through biological tissues as highfrequency acoustic waves, which is widely used in medicine as a diagnostic, therapeutic and operative tool.' Several well-designed studies have shown that pulsed ultrasonic waves can accelerate the fracture healing of long bones and the mandible.911

Although numerous studies attempted to shorten dental implant osseointegration time and to increase the osseointegration quality utilizing different methods, no publication is available concerning the effects of LIPU on dental implant osseointegration. The purpose of this pilot study was to evaluate the effects of LIPU on dental implant stability and osseointegration in a rabbit model using mechanical-histomorphometric methods and resonance-frequency analysis.

\section{MATERIALS AND METHODS}

The study was approved by the ethical review committee of Cukurova University Medical Scientific Research Center. Twelve skeletally mature, male New Zealand white rabbits 13.4 $\mathrm{kg} \pm 0.5)$ were used in the study. A total number of 24 implants were placed bilaterally in the tibiae of the subjects. One limb of each subject received daily LIPU application, while the other side received sham treatment. Therefore, each rabbit served as its own control. The study was carried on for 42 days. Two rabbits were sacrificed every week starting from the first week until the $6^{\text {th }}$ week. The histomorphometric analysis was conducted on 6 animals and mechanical tests were applied to the remaining 6 animals. The resonance frequency analysis was performed twice on each implant; right after the placement of the implant and on the sacrificing day. Statistical analysis was performed on the data gathered from the histomorphometric analysis and resonance frequency analysis.

\section{Surgical procedure}

General anesthesia was obtained by intramuscular injection of $35 \mathrm{mg} / \mathrm{kg}$ ketamine (Ketalar ${ }^{\circledR}$, Pfizer, Turkey) and $3 \mathrm{mg} / \mathrm{kg}$ xylazine (Rompun ${ }^{\circ}$, Bayer, Turkey). After positioning the animal in supine position, both limbs were prepared and draped bilaterally under aseptic conditions. Two $\mathrm{ml}$ of articaine with 1:200.000 epinephrine (Ultracain-DS®, Hoechst Marion Roussel, Turkeyl was injected supraperiosteally to provide local anesthesia and hemostasis. The implants were inserted in tibial metaphysis region. The bone surface was exposed via skin incision. The periosteum was incised and a periosteal flap was raised. One dental implant with a diameter of $4.1 \mathrm{~mm}$ and a length of $6.0 \mathrm{~mm}$ (Regular Neck, ITI ${ }^{\circledR}$, Straumann Institute, Waldenburg, Switzerland) was placed in each tibial metaphysis region of the rabbits bicortically. The implant sites were prepared using standard surgical technique recommended by the company with sharp drills. All drilling procedures were carried out under profuse sterile saline irrigation. The closure screws were placed after the implantation. The flap was closed in layers with the resorbable sutures (Vicryl $\AA$, Johnson\&Johnson, Brussels, Belgium) primarily leaving the implant submerged.

\section{Postoperative care}

Analgesic (Tramadol $1 \mathrm{mg} / \mathrm{kg}$ ) (Contramal $®$, Abdiibrahim, Turkey) and antibiotics (Cefazolin 25 $\mathrm{mg} / \mathrm{kg}$ ) (Cefamezin ${ }^{\circledR}$, Eczacibasi, Turkey) were administered intramuscularly preoperatively and twice per day during four postoperative days. The rabbits were housed in separated cages and were given a normal diet. Food and water intake and weights of the subjects were monitored and recorded daily.

\section{Resonance frequency analysis}

The implant stability was measured by resonance frequency analysis (RFA). The RFA test was applied twice to each implant; right after the 
placement of the implant and on the sacrificing day using a commercially available device. (Osstell@, Integration Diagnostics AB, Sweden) The device translates the RFA value into an index called the implant stability quotient (ISQ), which runs from 1 to 100 corresponding to the stability of the implant.

\section{Ultrasound application}

The application of LIPU was started on the second postoperative day. A commercially available therapeutic ultrasound device (Exogen 2000+, Smith \& Nephew Inc. Memphis, TN, USAl was used for the ultrasound treatment. The device transmits pulsed ultrasound signals with a $1.5 \mathrm{MHz}$ operation frequency consisting of a $200 \mu \mathrm{sec}$ burst of sine waves repeating at $1 \mathrm{kHz}$, which produces $30 \mathrm{~mW} / \mathrm{cm}^{2}$ average temporal and spatial intensity. The ultrasound applications were performed after placing the rabbit in a clean piece of cloth, which was hanging from a rigid place. The limb was left outside the cloth to perform the ultrasound application. The transducer was attached to the anterolateral surface of the tibia with Velcro ${ }^{\circledR}$ straps (Velcro Inc. Manchester, NH, USA). The animals, which have excessive movements, were sedated with intramuscular injection of 20 $\mathrm{mg} / \mathrm{kg}$ ketamine (Ketalar ${ }^{\circledR}$, Pfizer, Turkey). An investigator observed the whole treatment session to ensure the continuity of the application. Twenty minute sessions were repeated on daily basis for 6 weeks. The same procedure was repeated for the other limb of the subjects (control side) without activating the device.

The subjects were sacrificed on the planned day with an intravenous injection of $100 \mathrm{mg} / \mathrm{kg}$ sodium pentobarbitone (Pental $\AA$, Bilim, Turkey). The both tibiae were harvested from all animals and soft tissues were stripped off. Consequently, one experimental and one control tibia were obtained for every week.

\section{Mechanical testing}

The samples were wrapped by saline soaked gauze and stored at $-20^{\circ} \mathrm{C}$ and then thawed at room temperature before mechanical testing. The sections with a length of $1.5 \mathrm{~cm}$ of the implant bearing part of the tibia were harvested. A torque removal testing equipment that is specific to the tested implant system was prepared (Figure
1). The specimens were placed in the metal boxes $(6 \mathrm{~cm} \times 5 \mathrm{~cm})$ and embedded in an acrylic medium so that the implants could stand parallel to the horizontal line of the testing machine (Testometric $®$, M500 25 kN, Rochdale United Kingdom). A vertical force was applied with a crosshead speed of $1 \mathrm{~mm} /$ minute onto the metal arm that was fit on the implant by a custom abutment of the implant system until failure occurred. The point, where the load displacement graphic turns to a constant decline was accepted as the failure load. The removal torque value was calculated by the multiplication of the failure load value with the distance between the force point and the center of the implant.

\section{Histomorphometry}

The experimental and control tibiae of 6 rabbits were sectioned by comprising the implant and the surrounding $5 \mathrm{~mm}$ of tibial bone as the specimen. The specimens were fixed in 10\% buffered formalin, dehydrated in increasing concentrations of ethanol from $70 \%$ to $99 \%$ in 15 days and embedded in acrylic resin (Technovit ${ }^{\circ}$ 7200, Heraeus Kulzer $\mathrm{GmbH}$, Wehrheim, Germany). Transversal sections with a thickness of $40 \mu \mathrm{m}$ were prepared using an electric diamond saw and grinding system (Exakt, Norderstedt, Germany) and stained with toluidine blue. The digital images of the sections were obtained by a digital camera /Olympus ${ }^{\circledR}$ DP 70, Tokyo, Japan) attached to a microscope (Olympus ${ }^{\circledR}$ BX50, Tokyo, Japan) at a magnification rate of $40 \mathrm{x}$. The images were transferred to a PC and histomorphometric measurements were done by a personal computer software (WinTAS version 0.1 , University of Leeds, UK). Three slices from each specimen were analyzed and the mean values of the histomorphometry parameters were obtained for each subject.

For the histomorphometric analysis, the region that has direct contact with the implant was selected at a width of $100 \mu \mathrm{m}$. The bone-to-implant contact (BIC), bone volume (BV), bone area (BAr), bone perimeter (BPm), node termination number (NTm) and trabecular pattern factor (TbPf) were analyzed. The descriptions and equations of the parameters used in histomorphometric analysis are listed in Table 1. 


\section{Statistical analysis}

The subjects were grouped according to their sacrification weeks for making comparisons between the groups. The rabbits, which were sacrificed on the $1^{\text {st }}, 2^{\text {nd }}$ and $3^{\text {rd }}$ weeks, were considered in the early osseointegration period and the rabbits, which were sacrificed on the $4^{\text {th }}, 5^{\text {th }}$ and $6^{\text {th }}$ weeks, were considered in the late osseointegration period. The data regarding the mean values of the alterations in ISQ values and histomorphometry parameter scores were statistically analyzed using the unpaired student's t-test. A $p$ value that was smaller than 0.05 was considered as significant. No statistical analysis has been conducted on the mechanical test results due to limited number of subjects.

\section{RESULTS}

Three subjects were excluded from the study due to postoperative tibia fracture. The early exclusion of the 3 subjects necessitated a variation in the study design. Mechanical tests were performed on three rabbits instead of six rabbits, which were sacrificed on $2^{\text {nd }}, 4^{\text {th }}$ and $6^{\text {th }}$ weeks. No alteration was made in the design of the execution of the other analysis. Eighteen specimens were obtained at the end of the study. Histomorphometric analysis was performed on 12 specimens, mechanical testing was applied to 6 specimens and the RFA was applied to all specimens.

\section{Resonance frequency analysis}

The difference between the ISQ values measured at the time of sacrification and at the time of implant placement was used for making comparison between the LIPU and control groups. Alteration of ISQ values of the LIPU sides was higher when compared to their control sides in all weeks except in two subjects, which were sacrificed in the second and sixth weeks. The ISQ values of the LIPU group were increased at the time of sacrification in all weeks except for the first week. However, decrease of the ISQ values were recorded on first and the fourth weeks in subjects in the control group. The ISQ value alterations in the LIPU were higher than the control group both in the early and the late period of osseointegration. However, the difference was not statistically significant. The mean values of ISQ value alterations in the early and late periods were given in Table 2 .

\section{Mechanical test}

The removal torque values for the LIPU group were measured as $69.6 \mathrm{Ncm}, 90.4 \mathrm{Ncm}$ and 98.6 $\mathrm{Ncm}$ at $2^{\text {nd }}, 4^{\text {th }}$ and $6^{\text {th }}$ weeks, respectively. The values for the control group were measured as 67.4 Ncm, 79.6 Ncm and $84.2 \mathrm{Ncm}$, respectively (Table 3). No statistical analysis was conducted on the data due to the small sample size.

\section{Histomorphometry}

The mean values of the histomorphometry parameters of each subject were evaluated according to the sacrification period. The

Table 1. Bone histomorphometric parameters.

\begin{tabular}{|c|c|c|}
\hline Parameter & Units & Description/Equation \\
\hline Bone-implant contact (BIC) & $\%$ & $\begin{array}{l}\text { The percentage of implant length at which there is direct } \\
\text { bone-to-implant contact, without intervening tissue, along the } \\
\text { total length of the implant }\end{array}$ \\
\hline Bone volume (BV) & $\%$ & $\begin{array}{l}\text { Ratio of mineralized and un-mineralized bone volume to the } \\
\text { total tissue volume estimated from the analyzed section }\end{array}$ \\
\hline Bone area (BAr) & $\mathrm{mm}^{2}$ & The total bone area of the analyzed section \\
\hline Bone perimeter (BPm) & $\mathrm{mm}$ & $\begin{array}{l}\text { The total perimeter of bone in the analyzed section, including } \\
\text { void surfaces and excluding artificial edges }\end{array}$ \\
\hline Node termination (NTm) & - & End points in a trabecular network or free ends \\
\hline $\begin{array}{l}\text { Trabecular pattern factor } \\
\text { (TbPF) }\end{array}$ & - & (perimeter 1 - perimeter 2 )/larea 1 - area 2$)^{a}$ \\
\hline
\end{tabular}

${ }^{a} \mathrm{P} 1$ and $\mathrm{A} 1$ are from the original image; $\mathrm{P} 2$ and $\mathrm{A} 2$ are from the dilated image. ${ }^{9}$ 
histomorphometry test results in the early and late period for the LIPU and control group are shown in Table 4. The mean bone-implant contact value was significantly increased in the late osseointegration period for the LIPU group compared to the control group. Both the bone volume and the bone area values in the LIPU group showed a significant increase in the early osseointegration period but not in the late osseointegration period. Other histomorphometry parameters did not show any statistically difference between the two groups neither in the early nor in the late osseointegration period (Table 4) (Figure 2).

\section{DISCUSSION}

The histomorphometry parameters that were utilized in this study showed a positive effect of LIPU application on dental implant osseointegration specifically in the early osseointegration period. In vitro studies using cell cultures and research on experimental fractures in animal models have demonstrated a stimulatory effect of LIPU on intracellular activity, cytokine release and bone healing process. ${ }^{12,13}$ LIPU also has direct effect on cell physiology by increasing the incorporation of calcium ions in cartilage and bone cell cultures and by stimulating the expression of numerous genes involved in the healing process. ${ }^{9,14}$ In addition to modulating gene expression, ultrasound may enhance angiogenesis and increase blood flow around the fracture. ${ }^{15}$ Besides these molecular interactions, the acoustic pressure waves facilitate fluid flow, which increases nutrient delivery and waste removal lacoustic streaming phenomenon), thus stimulating proliferation and differentiation of the fibroblasts, chondroblasts

Table 2. Mean normalized values of ISQ alterations IISQ value at time of sacrification- ISQ value at the time of implantation).

\begin{tabular}{lcc}
\hline Group & $\mathrm{n}$ & Mean \pm SD \\
\hline Control group. Early period* & 4 & $-4.75 \pm 11.50$ \\
Control group. Late period** & 5 & $2.00 \pm 5.08$ \\
LIPU group. Early period* & 4 & $1.25 \pm 8.85$ \\
LIPU group. Late period** & 5 & $7.40 \pm 4.93$ \\
\hline
\end{tabular}

SD: Standard deviation

Early Period: Subjects sacrificed on the $1^{\text {st }}, 2^{\text {nd }}$ and $3^{\text {rd }}$ weeks. Late Period: Subjects sacrificed on the $4^{\text {th }}, 5^{\text {th }}$ and $6^{\text {th }}$ weeks. *: $\mathrm{P}>.05 ;{ }^{* *}: \mathrm{P}>.05$ and osteoblasts. ${ }^{9,16}$ Although the exact mechanism of how LIPU interacts with living tissue and stimulates bone healing remains unclear, these well documented studies may indicate that LIPU may stimulate bone regeneration, shorten the total osseointegration time of dental implants and promote the osseointegration quality. We aimed to investigate the effects of LIPU application on dental implant osseointegration by using the RFA method, mechanical measurement of implant stability by a custom designed model and histomorphometric assessment.

There are many studies in the literature that evaluate implant osseointegration using the rabbit tibiae model. ${ }^{17-19}$ Both the tibial metaphysis and diaphysis regions have been used for implant placement in previous studies. In this study, the metaphysis region was chosen due to safe proximity to the articular surface and less risk of bone fracture compared to the diaphysis region. The implants were left submerged to prevent any extrinsic trauma and no sign of exposure was observed during the healing period.

Different techniques have been proposed for the measurement of implant stability like Periotest ${ }^{\circledR}$ (Gulden, Bensheim, Germanyl or Dental Fine Tester ${ }^{\circledR}$ (Kyocera, Kyoto, Japan) systems. However, their lack of resolution, poor sensitivity and susceptibility to operator variables have been criticized. ${ }^{20}$ Recently, RFA has become a popular option to provide an objective measurement of implant stability. In our study, we utilized the Osstell $®$ device, which translates the RFA value into implant stability quotient index. Classically, the ISQ value has been found to vary between 40 and 80 and higher ISQ values correspond to higher implant stability. ${ }^{21}$

The resonance frequency analysis provides valuable clinical objective data of implant stability. A substantial increase or decrease in implant stability could be detected with this method that otherwise could not be clinically perceived.22,23 Nedir et $\mathrm{al}^{21}$ stated that the RFA method was not

Table 3. Torque removal test results of each animal (N.cm).

\begin{tabular}{lccc}
\hline Sample & $2^{\text {nd }}$ week & $4^{\text {th }}$ week & $6^{\text {th }}$ week \\
\hline LIPU & 69.6 & 90.4 & 98.6 \\
Control & 67.4 & 79.6 & 84.2 \\
\hline
\end{tabular}

(LIPU: Low-intensity ultrasound) 
reliable in identifying mobile implants. Therefore, implant stability could be reliably determined for implants with an ISQ $\geq 47$. The RFA results of the present study are parallel to the findings of Nedir et $a_{1}{ }^{21}$ because all of the inserted implants were clinically stable and all of the ISQ values recorded during the 6 week study interval were between 54 and 79. The alterations in the ISQ values in the early and the late osseointegration periods have been compared between the groups. Four samples from each group were included in the early osseointegration period and five samples from each group were included in the late osseointegration period. A mild increase in the ISQ values has been detected in the LIPU group in both the early and late periods. However, the difference was not statistically significant. Thus,

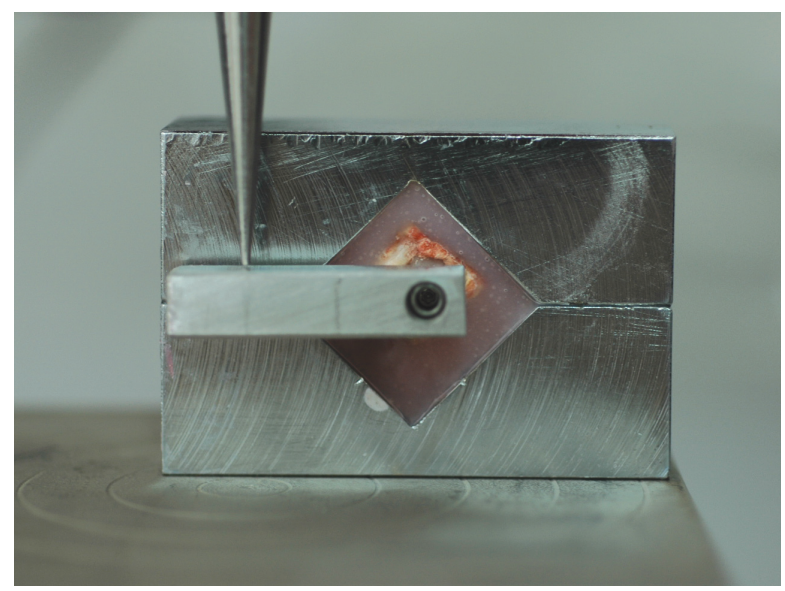

Figure 1. Torque removal testing equipment specific to the tested implant system. the RFA findings of this study do not imply a strong evidence of positive effects of LIPU on dental implant stability.

The torque removal testing is a well-known method in experimental animal studies, especially in rabbit tibia and femur. ${ }^{24}$ Torque removal forces have been used as a biomechanical measure of anchorage or have been interpreted as an increase in the strength of bony integration. ${ }^{4}$ In this study, the resistance to reverse the torque rotation of the LIPU applied implants were compared with sham treated implants. For this purpose, we prepared a custom made testing equipment consisting of a metal arm that was fit on the implant by a custom abutment of the implant system, because there is no standard method in wide spread use at the current time. ${ }^{25}$

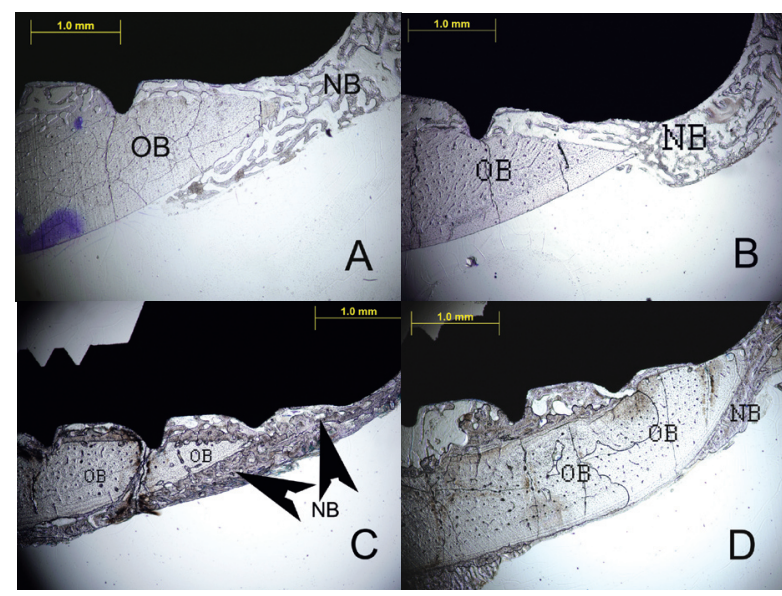

Figure 2. The histologic sections of $2^{\text {nd }}$ week LIPU (a), $2^{\text {nd }}$ week control (b), $4^{\text {th }}$ week LIPU (c), $4^{\text {th }}$ week control (d) (Toluidine BlueX40). Note the new bone formation (black arrows) outside the original bone in Figure $2 C$. $\quad(O B=$ original bone, $N B=$ new bone).

Table 4. Mean scores of the histomorphometry parameters for the control and LIPU groups.

\begin{tabular}{|c|c|c|c|c|c|c|}
\hline Group & $\mathrm{BIC}(\%)$ & $\mathrm{BV}(\%)$ & $\operatorname{Bar}\left(\mathrm{mm}^{2}\right)$ & BPm(mm) & NTm(count) & TbPF(count) \\
\hline $\begin{array}{l}\text { Control, } \\
\text { Early period (n=3) }\end{array}$ & $64.96 \pm 19.40$ & $18.78 \pm 9.19^{* *}$ & $.008 \pm 0.004 \uparrow$ & $5.93 \pm 2.48$ & $207.45 \pm 70.1$ & $593.76 \pm 169.52$ \\
\hline $\begin{array}{l}\text { Control, } \\
\text { Late period ( } n=3)\end{array}$ & $65.92 \pm 6.53^{*}$ & $38.52 \pm 9.84$ & $.018 \pm 0.004$ & $11.04 \pm 1.2$ & $243.61 \pm 41.01$ & $629.20 \pm 99.87$ \\
\hline $\begin{array}{l}\text { LIPU, } \\
\text { Early period (n=3) }\end{array}$ & $74.12 \pm 15.19$ & $35.77 \pm 2.8^{* *}$ & $.017 \pm 0.0019$ & $9.04 \pm 2.26$ & $206.16 \pm 127.8$ & $541.73 \pm 112$ \\
\hline $\begin{array}{l}\text { LIPU, } \\
\text { Late period }(n=3)\end{array}$ & $83.62 \pm 3.66^{*}$ & $54.26 \pm 8.42$ & $.025 \pm 0.004$ & $11.70 \pm 0.63$ & $175.50 \pm 56.76$ & $455.89 \pm 128.81$ \\
\hline
\end{tabular}

Early Period: Subjects sacrificed on the $1^{\text {st }}, 2^{\text {nd }}$ and $3^{\text {rd }}$ weeks.

Late Period: Subjects sacrificed on the 4 th, $5^{\text {th }}$ and $6^{\text {th }}$ weeks.

BIC: Bone implant contact, BV: Bone volume, BAr: Bone area, BPm: Bone perimeter, NTm: Node termination number, TbPF: Trabecular pattern factor.

$*, * *, \mathfrak{l}=\mathrm{P}<.05$ 
Both the LIPU and the sham treated implants showed a gradual increase in the torque removal forces by time. When compared with the sham treated implants, the three implants in the LIPU group were more resistant to torque removal forces on the $2^{\text {nd }}, 4^{\text {th }}$ and $6^{\text {th }}$ weeks. The higher resistance to removal torque forces indicates a better osseointegration. ${ }^{25}$ Therefore, LIPU application may have led to a better osseointegration of the implants. However, the lack of statistical analysis for the mechanical test results hinders to withdraw any absolute conclusion.

Histomorphometry is a valuable method for the assessment of periimplant tissues that provides quantitative results. In general, the following two parameters are of major interest in evaluating the bone response close to the implant surface; the percentage of bone-to-implant contact and bone density, which can be defined as the percentage of bone fill in predetermined areas around the implant. ${ }^{26}$ The percentage of bone-to-implant contact provides information about the fixation of the implant in the bone, whereas the bone density around the implant reflects the degree of compatibilityand integration of the inserted implant under certain defined conditions. ${ }^{26}$ The software that was used in this study estimates the open ending trabecular network for the determination of terminus number, which is a valuable parameter for trabecular interconnection. Terminus number measurements give high values when there is a high amount of open ending trabecular network. As the bone tissue matures, these open ended trabeculae will close and lower terminus number values will be recorded. In the first three weeks of the present study, LIPU applied sides had a higher inclination followed by a stronger declination of terminus number values when compared to their control sides. However, the difference was not statistically significant.

Trabecular pattern factor, proposed by Hahn et $\mathrm{al}^{27}$ is another definitive parameter for trabecular interconnection. Web-like bony network exhibits many thin, branching-free endings and this will negatively influence the trabecular connectivity measurements. Thus, a lower trabecular pattern factor corresponds to a higher bone density. ${ }^{28}$ The results of our study did not show any significant effect of LIPU application on trabecular pattern factor values both in the early and late osseointegration period.

Significant increase of bone area and bone volume values has been observed in the early osseointegration period in the LIPU group. These results are in accordance with previous studies suggesting positive influence of LIPU treatment on early period of bone healing comprising the inflammatory and callus formation phases. ${ }^{29,30}$ The LIPU treated subjects showed significantly higher bone implant contact ratio in the late osseointegration period but not in the early period. According to these results it may be concluded that although LIPU treatment increases the bone volume and bone area even in the early postoperative period, changes in bone to implant contact occurs after the $3^{\text {rd }}$ week of application.

Biophysical stimulation on bone tissue has been investigated both experimentally and clinically by numerous studies. Positive outcomes have been reported by many authors for the treatment of bone infections, delayed unions and non-union of fractures, bone necrosis and integration of intercalary bone grafts. ${ }^{7}$ Several studies demonstrated that LIPU stimulates osteogenesis

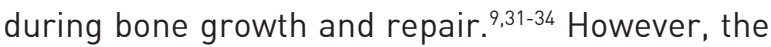
exact mechanism of how LIPU interacts with living tissue and stimulates bone healing stays unclear. Korstjens et al ${ }^{35}$ reported that LIPU has stimulatory effect on bone formation and the region with the highest cell-activity seemed to be most sensitive for LIPU stimulation within a bone tissue. Tanzer et $a^{36}$ showed that LIPU can substantially increase bone growth into porous intramedullar implants. In our study, histomorphometry parameters showed a possible stimulatory effect of LIPU on bone regeneration and osseointegration around dental implants.

\section{CONCLUSIONS}

RFA scores did not imply any significant contribution of LIPU treatment in dental implant osseointegration and the lack of statistical analysis of the mechanical test results hinders to withdraw any conclusion. However, bone area, bone volume and bone-implant contact ratio values, which are significant parameters of histomorphometry assessments, have increased in the experimental group, when compared to the control group. Thus, within the limitation of this pilot study, we suggest 
that LIPU application may accelerate and promote bone healing around dental implants leading to a higher quality and faster osseointegration. Limitations of the study were the use of tibial bone instead of maxillofacial bones and decreased sample size due to postoperative tibia fracture resulting with the lack of statistical analysis of the mechanical test results. LIPU application is simple to use individually and no side effects of the treatment have been reported so far. Therefore, it seems possible to use this application clinically to strengthen dental implant osseointegration and stability. Due to the limitations of this study, further well-designed animal studies are needed to provide statistically approved scientific evidence for this purpose.

\section{ACKNOWLEDGEMENTS}

This research was supported and funded by Cukurova University academic research projects unit (project number DHF2004BAP2). Biomechanical tests and undecalcified histological sections were performed in the laboratories of the division of dental research of Cukurova University, Faculty of Dentistry.

\section{REFERENCES}

1. Brånemark PI, Zarb G, Albreksson T. Tissue-integrated prosthesis. In: Brånemark $\mathrm{Pl}$, ed. Osseointegration in clinical dentistry. Chicago, Il: Quintessence Publishing Co., 1985:11-76.

2. Buser D, Schenk RK, Steinmann S, Fiorellini JP, Fox CH, Stich $H$. Influence of surface characteristics on bone integration of titanium implants. A histomorphometric study in miniature pigs. J Biomed Mater Res 1991;25:889902.

3. Ericsson I, Johansson CB, Bystedt H, Norton MR. A histomorphometric evaluation of bone-to-implant contact on machine-prepared and roughened titanium dental implants. A pilot study in the dog. Clin Oral Implan Res 1994;5:202-206.

4. Klokkevold PR, Johnson P, Dadgostari S, Caputo A, Davies JE, Nishimura RD. Early endosseous integration enhanced by dual acid etching of titanium: a torque removal study in the rabbit. Clin Oral Implan Res 2001;12:350-357.

5. Nakamura H, Saruwatari L, Aita H, Takeuchi K, Ogawa T. Molecular and biomechanical characterization of mineralized tissue by dental pulp cells on titanium. $J$ Dent Res 2005;86:515-520.
6. Liu Y, DE Groot K, Hunkizer EB. BMP-2 liberated from biomimetic implant coatings induces and sustains direct ossification in an ectopic rat model. Bone 2005;36:745-757.

7. Fini M, Giavaresi G, Setti S, Martini L, Torricelli $P$, Giardino R. Current trends in the enhancement of biomaterial osteointegration: Biophysical stimulation. Biomaterials 2004;27:681-690.

8. Tanzer M, Kantor S, Bobyn JD. Enhancement of bone growth into porous intramedullary implants using non-invasive low intensity ultrasound. J Orthop Res 2001;19:195-199.

9. Rubin C, Bolander M, Ryabi JP, Hadjiargyrou M. The use of low-intensity ultrasound to accelerate the healing of fractures. J Bone Joint Surg Am 2001;83:259-270.

10. Warden SJ, Bennell KL, Mcmeeken JM, Wark JD. Acceleration of fresh fracture repair using the sonic accelerated fracture healing system (SAFHS): a review. Calcif Tissue Int 2000;66:157-163.

11. Erdoḡan Ö, Esen E, Üstün Y, Kürkçü M, Akova T, Gönlüșen $G$, Uysal H, Cevlik F. Effects of low-intensity pulsed ultrasound on healing of mandibular fractures: An experimental study in rabbits. J Oral Maxillofac Surg 2006;64:180-188.

12. Chapman I, Macnally NA, Tucker S. Ultrasound-induced changes in the rates of influx and efflux of potassium ions in rat thymocytes in vitro. Ultrasound Med Biol 1980;6:4758.

13. Li JK, Chang WH, Lin JC, Ruaan RC, Liu HC, Sun JS. Cytokine release from osteoblasts in response to ultrasound stimulation. Biomaterials 2003;24:2379-2385.

14. Yang KH, Parvizi J, Wang SJ, Lewallen DG, Kinnick RR, Greenleaf JF, Bolander ME. Exposure to low-intensity ultrasound increases aggrecan gene expression in a rat femur fracture model. J Orthop Res 1996;14:802-809.

15. Barzelai S, Sharabani-Yosef O, Holbova R, Castel D, Walden R, Engelberg S, Scheinowitz M. Low-intensity ultrasound induces angiogenesis in rat-limb ischemia. Ultrasound Med Biol 2006;32:139-145.

16. Hadjiargyrou M, Mcleod K, Ryaby Jp, Rubin C. Enhancement of fracture healing by low intensity ultrasound. Clin Orthop Relat Res 1998;355:216-229.

17. Hisatake $M$, Manabe $M$, Kurachi $Y$, Nagumo $M$. Osseointegration of dental implants in rabbit bone with low mineral density. J Oral Maxillofac Surg 1997;55:351-361.

18. Park JW, Park KB, Suh JY. Effects of calcium ion incorporation on bone healing of Ti6Al4V alloy implants in rabbit tibiae. Biomaterials 2007;28:3306-3313.

19. Suh JY, Jeung OC, Choi BJ, Park JW. Effects of a novel calcium titanate coating on the osseointegration of blasted endosseous implants in rabbit tibiae. Clin Oral Implants Res 2007;18:362-369. 
20. Meredith N. Assessment of implant stability as a prognostic determinant. Int J Prosthodont 1998;11:491-501.

21. Nedir R, Bischof M, Szmukler-Moncler S, Bernard JP, Samson J. Predicting osseointegration by means of implant primary stability. A resonance frequency analysis study with delayed and immediately loaded ITI SLA implants. Clin Oral Implants Res 2004;15:520-528.

22. Friberg B, Sennerby L, Linden B, Grondahl K, Lekholm U. Stability measurements of one-stage Brånemark implants during healing in mandibles. A clinical resonance frequency analysis study. Int J Oral Maxillofac Surg 1999;28:266-272.

23. Friberg B, Sennerby L, Meredith N, Lekholm U. A comparison between cutting torque and resonance frequency measurements of maxillary implants. A 20month clinical study. Int J Oral Maxillofac Surg 1999;28:297303.

24. Martinez-Gonzalez JM, Garcia-Saban F, Ferrandiz-Bernal J, Gonzalo-Lafuente Jc, Cano-Sanchez J, Barona-Dorado C. Removal torque and physico-chemical characteristics of dental implants etched with hydrofluoric and nitric acid. An experimental study in Beagle dogs. Med Oral Patol Oral Cir Bucal 2006;11:E281-E285.

25. Nakamura T, Nishiguchi S. Tensile testing of bone implant interface. In: An YH and Draughn RA, eds. Mechanical testing of bone and the bone-implant interface, Washington D.C., CRC Press LLC., 2000:489-497.

26. Weinstein RS. Human bone biopsy. In: Yuehuei HA and Kylie LM eds. Handbook of histology methods for bone and cartilage. Totowa-New Jersey, Humana Press Inc. 2003:129-143.

27. Hahn M, Vogel M, Pompesius-Kempa M, Delling G. Trabecular bone pattern factor-a new parameter for simple quantification of bone microarchitecture. Bone 1992;13:327-330.

28. Suba Z, Takacs D, Matusovits D, Barabas J, Fazekas A, Szabo G. Maxillary sinus flooe grafting with $\beta$-tricalcium phosphate in humans: density and microarchitecture of the newly formed bone. Clin Oral Implants Res 2006;17:102108.

29. Wang SJ, Lewallen DG, Bolander ME, Chao EY, Ilstrup DM, Greenleaf JF. Low intensity ultrasound treatment increases strength in a rat femoral fracture model. $J$ Orthop Res 1994;12:40-47.

30. Hantes ME, Mavrodontidis AN, Zalavras CG, Karantanas $\mathrm{AH}$, Karachalios T, Malizos KN. Low-intensity transosseous ultrasound accelerates osteotomy healing in a sheep fracture model. J Bone Joint Surg Am 2004;86:2275-2282.

31. Saparado JA, Albanese SA, Chase SE. Electromagnetic effects on bone formation at implants in the medullary canal in rabbits. J Orthop Res 1990;8:685-693.
32. Duarte LR. The stimulation of bone growth by ultrasound. Arch Orthop Trauma Surg 1983;101:153-159.

33. Wang SJ, Lewallen DG, Bolander ME, Chao EY, Ilstrup DM, Greenleaf JF. Low intensity ultrasound treatment increases strength in a rat femoral fracture model. $J$ Orthop Res 1994;12:40-47.

34. Reher P, Elbeshir EL-NI, Harvey W, Meghji S, Harris M. The stimulation of bone formation in vitro by therapeutic ultrasound. Ultrasound Med Biol 1997;23:1251-1258.

35. Korstjens CM, Nolte PA, Burger EH, Albers GHR, Semeins CM, Aartman IHA, Goei SW, Klein-Nulend J. Stimulation of bone cell differentiation by low-intensity ultrasound - a histomorphometric in vitro study. JOrthop Surg 2004;22:495500 .

36. Tanzer M, Harvey E, Kay A, Morton P, Bobyne JD. Effect of noninvasive low intensity ultrasound on bone growth into porous-coated implants. J Orthop Res 1996;14:901-906. 